\title{
ANÁLISE DOS PRINCÍPIOS APLICÁVEIS À RECUPERAÇÃO JUDICIAL DAS EMPRESAS CONCESSIONÁRIAS DE SERVIÇO PÚBLICO
}

\author{
Bruna Marchese e Silva* \\ Manoel de Queiroz Pereira Calças*
}

Resumo: Ao proceder a uma análise sistemática dos conceitos e principais características do serviço público e da recuperação judicial de empresas concessionárias de serviços públicos, o presente trabalho científico tem por fim analisar a importância dos princípios que regem a matéria. Os Princípios da Preservação e da Função Social da Empresa, aliados aos Princípios da Supremacia do Interesse Público, da Essencialidade, da Necessidade e da Continuidade do Serviço Público constituem arcabouço principiológico fundamental para interpretação e aplicação das normas legais e contratuais em casos de recuperação judicial de concessionárias de serviços públicos

Palavras-chave: Princípios; Recuperação Judicial; Concessionárias; Serviço Público; Função Social.

\section{ANALYSIS OF THE PRINCIPLES APPLICABLE TO THE JUDICIAL RECOVERY OF PUBLIC SERVICE CONCESSIONAIRES}

Abstract: By carrying out a systematic analysis of the concepts and main characteristics of the public service and the judicial reorganization of public service concessionaires, this scientific work aims to analyze the importance of the principles that govern the matter. The Principles of Preservation and Social Function of the Company, together with the Principles of Essentiality, Necessity and Continuity of the Public Service constitute a fundamental principle for the interpretation and application of legal and contractual rules in cases of judicial reorganization of public service concessionaires

Keywords: Principles; Judicial Recovery; Concessionaires; Public Service; Social Role

\section{INTRODUÇÃO}

O presente artigo propõe a investigação científica, sob o ponto de vista do Direito, da recuperação judicial das empresas concessionárias de serviços públicos e sua correlação com os princípios da função social e preservação da empresa. Como é cediço, há um interesse social que decorre da preservação da empresa, princípio este, aliás, insculpido no artigo 47 da Lei $n^{\circ} 11.101 / 05$, segundo o qual:

\footnotetext{
* Mestranda em Direito Empresarial pela Universidade Nove de Julho- UNINOVE (2021- atual). Atua como Juíza de Direito no Tribunal de Justiça do Estado de São Paulo - TJ/SP (junho/2009 - atual). E-mail: bmarchesemagis@gmail.com.

* Professor de Direito Empresarial da Universidade de São Paulo e da Universidade Nove de Julho. Desembargador aposentado do Tribunal de Justiça do Estado de São Paulo. Presidente do Tribunal de Justiça do Estado de São Paulo no biênio 2018-2019. E-mail: manoel-pereira@uol.com.br.
} 
A recuperação judicial tem por objetivo viabilizar a superação da situação de crise econômico-financeira do devedor, a fim de permitir a manutenção da fonte produtora, do emprego dos trabalhadores e dos interesses dos credores, promovendo, assim, a preservação da empresa, sua função social e o estímulo à atividade econômica (BRASIL, 2005, art. 47).

Dentro deste contexto, defende-se a superação da teoria do dualismo pendular, de modo que a interpretação das regras da recuperação judicial não deve prestigiar os interesses de credores ou de devedores, mas deve sim procurar preservar e viabilizar os benefícios sociais e econômicos que decorrem da manutenção da atividade empresarial. Nesse sentido, diante das várias possibilidades interpretativas da lei oferecidas pela técnica jurídica, deve-se acolher como adequada aquela que prestigiar de forma mais importante a própria finalidade do instituto da recuperação judicial.

Partindo-se de tais premissas, busca-se com o presente trabalho científico procederse a uma aprofundada análise da recuperação judicial de empresas que, por meio de contrato de concessão, prestam um serviço público. Daí exsurge a necessidade de proceder-se a uma interpretação em conjunto e de modo sistemático das normas legais e contratuais vigentes, cotejando-as com as particularidades do serviço público prestado, com a real situação econômica das recuperandas, bem como sendo necessário perquirir-se, dentro deste contexto, se são válidos os termos do contrato e garantias prestadas entre empresa e poder concedente.

A função social da empresa, reconhecida pela Lei, pela doutrina e jurisprudência pátria, bem como a necessidade de sua preservação, segundo entendo, devem ser ainda mais valoradas quando se está diante de empresa que desempenha a execução, manutenção e ampliação de serviços públicos de extrema relevância, em face dos quais se observa os princípios da continuidade, essencialidade e necessidade. 


\section{DO SERVIÇO PÚBLICO}

\subsection{Conceito e Características}

Muito embora exista quem defenda que o conceito de serviço público não é estático, mas sim mutável em razão das diferentes dinâmicas sociais, políticas e econômicas em que se insere, há pontos em comum que o identificam independentemente de qualquer contexto. Assim, há serviço público toda vez que o Estado assuma obrigatoriamente, ainda que direta ou indiretamente, a obrigação de satisfazer determinadas necessidades coletivas.

Segundo Celso Antônio Bandeira de Melo:

Serviço público é toda atividade de oferecimento de utilidade ou comodidade material destinada à satisfação da coletividade em geral, mas fruível singularmente pelos administrados, que o Estado assume como pertinente a seus deveres e presta por si mesmo ou por quem lhe faça as vezes, sob um regime de Direito Público portanto, consagrador de prerrogativas de supremacia e de restrições especiais -, instituído em favor dos interesses definidos como públicos no sistema normativo (MELLO, 2021, p. 657).

Há, portanto, um aspecto material representado pela noção de que serviço público é toda prestação de utilidade pública que o Estado assume como própria, fruível singularmente pelos administrados, e que satisfaça interesses coletivos.

O aspecto formal, por seu turno, diz respeito ao regime jurídico-administrativo a que se submete o serviço público, que é o de direito público.

E, do ponto de vista do aspecto subjetivo, possível dizer que serviço público é aquele prestado direta ou indiretamente pelo Estado, sob o regime de concessão ou permissão.

Neste sentido, dispõe o artigo 175 da Constituição Federal que:

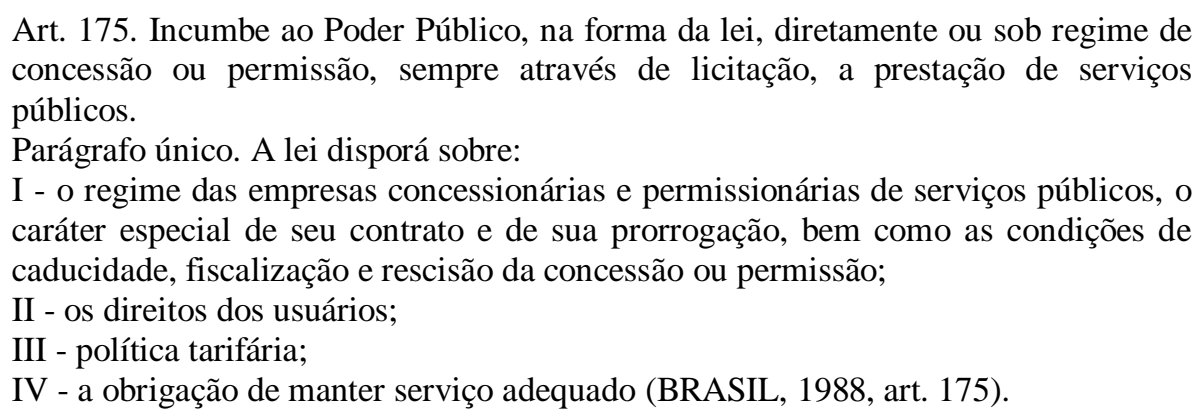

Em sendo assim, é a norma constitucional que define um serviço como sendo público de modo que, na omissão do texto legal, a exploração da atividade será exercida livremente pela iniciativa privada. Também é a Carta Magna que disciplina, em suma, a competência para prestação de serviços públicos entre a União, Estados e Municípios, cabendo a cada um, respectivamente, a prestação daqueles de interesse geral, regional e local, ofertando rol 
exemplificativo nos artigos $21,23,25, \S \S 1^{\circ}$ e $2^{\circ}$, e 30 da Constituição Federal (BRASIL, 1988).

De se ressaltar que a análise constitucional traz à lume a existência de serviços públicos que são privativos do Estado - aqueles enumerados na Constituição Federal e que podem ser prestados direta pelo Estado ou indiretamente através de delegação aos particulares (via concessão, permissão ou autorização) - e outros não privativos, ou seja, aqueles que podem ser livremente prestados por particulares, a exemplo da saúde e educação.

Ainda para fins de classificação, uniformiza-se a doutrina ao admitir a figura dos serviços públicos propriamente ditos, aqueles essenciais e que não admitem delegação, em contraponto aos serviços de utilidade pública, que são aqueles que melhoram a vida do cidadão e admitem delegação. Também classificam-se os serviços públicos em gerais (uti universi), que são aqueles prestados à coletividade como um todo, indivisíveis e mantidos com a receita de impostos, e individuais ou específicos (uti singuli), que são prestados à todos mas fruíveis individualmente, sendo, portanto, divisíveis, os quais podem ser compulsórios e, neste caso, remunerados por taxa, ou facultativos, cuja remuneração é feita por tarifa, admitindo-se a cobrança de taxa mínima apenas na primeira situação.

\subsection{Princípios}

Feitas tais considerações, ganha relevância o estudo dos princípios que regem o serviço público. E, no direito comparado, a doutrina francesa enumera os princípios da mutabilidade, continuidade e igualdade como sendo gerais aos serviços públicos (CHAPUS, 1992).

No Brasil, contudo, Hely Lopes Meirelles (2018) ensina serem cinco os princípios aplicáveis à matéria. São eles: princípio da permanência (nome dado ao princípio da continuidade), da generalidade (sinônimo do princípio da igualdade), da eficiência, da modicidade (que pressupõe a fixação de tarifas a preços justos e razoáveis) e da cortesia.

Por outro lado, para Celso Antonio Bandeira de Mello (2021), em ampla análise do tema, são dez os princípios que compõe do regime jurídico dos serviços públicos. E, dada a relevância da análise principiológica para compreensão do tema, cumpre enumerá-los: a) princípio do dever inescusável do Estado em promover-lhe a prestação, direta ou indiretamente através de concessão, permissão ou autorização; b) princípio da supremacia do interesse público, o qual pressupõe como "norte obrigatório" de qualquer atuação do estado a 
busca do interesse da coletividade; c) princípio da adaptabilidade, o qual pressupõe que deverá o Poder Público se modernizar e atualizar na prestação do serviço público; d)princípio da universalidade, segundo o qual o serviço público é prestado a todos; e) princípio da impessoalidade, ou seja, veda-se qualquer forma de discriminação na prestação do serviço; f) princípio da continuidade, de modo que não pode o serviço público ser interrompido ou suspenso; g) princípio da transparência, segundo o qual as pessoas devem ter acesso à todas as informações relacionadas ao serviço; h)princípio da motivação, ou seja, todas as decisões pertinentes ao serviço público devem ser fundamentadas e motivadas por seus agentes; i)princípio da modicidade da remuneração, o qual possui inclusive previsão legal no artigo $6^{\circ}$, $\S 1^{\circ}$ da Lei $8.987 / 95$ e tem por finalidade vedar que a taxa ou tarifa cobrada pelos serviços públicos exceda valores razoáveis e causem a marginalização social (BRASIL, 1995a); e, por fim, o j) princípio do controle interno e externo, segundo o qual as condições da prestação do serviço público são passíveis de controle por mecanismos internos e externos à sua estrutura.

A relevância do estudo dos princípios é inegável e conduz à uma melhor compreensão da matéria. No caso em tela, os princípios aplicáveis aos serviços públicos efetivamente demonstram sua importância dentro de determinada sociedade em que inseridos, já que acabam por refletir, conforme dito, as opções políticas e sociais do próprio Estado, bem como o grau de sua interferência na vida privada das pessoas.

Em sendo assim, pode-se dizer que em nosso país os serviços públicos possuem inegável importância, sendo garantidos à universalidade de pessoas dada sua essencialidade, mediante o pagamento de tarifas que, por sua natureza, devem ser módicas de modo a não gerarem exclusão social.

Dentro deste contexto, possível dizer que, além dos efeitos sentidos pelos trabalhadores da própria sociedade empresária, a crise econômica experimentada por empresa prestadora de serviço público gera efeitos que são sentidos de forma macro, pelo mercado e também por toda a sociedade afetada pela prestação do serviço.

\subsection{Concessão de Serviço Público}

Como é cediço, a prestação do serviço público pode se dar de modo indireto, ou seja, quando não é realizado diretamente pelo Estado, mas sim por pessoas estranhas ao aparelho estatal (a exemplo de particulares ou entidades da administração indireta), por meio dos 
institutos da autorização, permissão ou concessão, segundo ditame constitucional (BRASIL, 1988, arts. 21 e 175).

Apenas para fins ilustrativos, distinguem-se a permissão como sendo a delegação precária e revogável, mediante contrato precedido de licitação, da prestação de serviço público pelo poder concedente a uma pessoa física ou jurídica que possua capacidade para exercê-lo, em contrapartida ao instituto da autorização, que também é uma modalidade de delegação de serviço, a título precário, discricionário e sem licitação, para realização de uma atividade de interesse predominantemente privado ou a utilização de um bem público.

Por outro lado, e considerando-se o escopo do presente trabalho, precisos são os ensinamentos de Bandeira de Mello, que observa:

Concessão de serviço público é o instituto através do qual o Estado atribui o exercício de um serviço público a alguém que aceita prestá-lo em nome próprio, por sua conta e risco, nas condições fixadas e alteráveis unilateralmente pelo Poder Público, mas sob garantia contratual de um equilíbrio econômico-financeiro, remunerando-se pela própria exploração do serviço, em geral e basicamente mediante tarifas cobradas diretamente dos usuários do serviço (MELLO, 2021, p. 678).

Para Diogenes Gasparini, por seu turno:

Concessão de serviço público é o contrato administrativo pelo qual a Administração Pública transfere, sob condições, a execução e exploração de certo serviço, que lhe é privativo, a terceiro que para isso manifeste interesse e que será remunerado adequadamente mediante a cobrança, dos usuários, de tarifa previamente por ele aprovada (GASPARINI, 2004, p.312).

Tem-se, assim, que é através da concessão que o poder concedente (União, Estados ou Municípios, a depender de quem seja o responsável pela atividade), por meio de um processo licitatório, na modalidade de concorrência, atribui à prestação do serviço à concessionária pessoa jurídica ou a um consórcio de empresas que demonstrem aptidão para sua prestação, por sua conta e risco, por prazo determinado, e com remuneração representada pela própria exploração do serviço, por meio do pagamento de tarifa, e instrumentalizado pelo contrato administrativo.

A fim de dar cumprimento ao comando constitucional, foi editada a Lei $\mathrm{n}^{\circ}$ 8.987/1995 - Lei das Concessões - que disciplina em larga escala os contratos de concessões no país, dada sua especificidade e regramento jurídico próprio, excluindo-se, contudo, de sua abrangência os serviços de radiodifusão sonora e de sons e imagens (rádio e televisão) que permanecem disciplinados pela Lei 4.177/62 e 5.785/72, e a concessão de energia elétrica, esta abrangida pela Lei 9.074/95 (BRASIL, 1995a, 1995b, 1962, 1972). 
Não se desconhece que o regime jurídico de direito privado possui como norte os princípios da autonomia privada, da função social do contrato e a boa-fé, não havendo para as partes contratantes supremacia ou submissão de uma à outra. Diferentemente, contudo, é o que ocorre no âmbito público no tocante aos contratos administrativos firmados entre poder concedente e empresas concessionárias, situação em que há prevalência do interesse coletivo sobre o particular e, em razão disso, maiores poderes concedidos aos primeiros. E, exatamente por isso, conforme se verá adiante, ganha especial relevo a aplicação dos princípios como vetores interpretativos aos casos "sub judice".

A lei de regência da matéria estabelece também que as concessões podem ou não serem precedidas de obra pública. No primeiro caso, a título de exemplo, tem-se a exploração de estradas em que é feita a construção ou melhoramento de rodovias e cobrança de pedágios e, no segundo caso, o fornecimento de energia elétrica, de modo que, em ambos os casos, a legislação traz as definições legais em seus artigos $2^{\circ}$, incisos II e III - as quais são, inclusive, objeto de críticas de Celso Antonio Bandeira de Mello dada as imprecisões terminológicas nelas contidas (MELLO, 2021, p. 683).

Assim, tem-se que apenas haverá concessão de serviço público em relação à serviços próprios e privativos do Estado, sendo estes considerados res extra commercium, ou, em outras palavras, inegociáveis pelo poder público, não havendo que se falar em transferência de titularidade do serviço, que nunca será detido pelo particular, mas tão somente por ele exercido.

Sob outro ângulo, tem-se que tais serviços também não podem ser aqueles aos quais a Carta Magna reservou a titularidade e exploração exclusiva apenas pelo poder público, a exemplo do serviço postal e correio aéreo nacional, os quais não admitem delegação.

A relação entre poder concedente e concessionária, pois, possui natureza jurídica complexa dado o objeto do contrato de concessão que os une, ou seja, a prestação do serviço público. Assim, há neste relacionamento entre as partes atos regulatórios impostos unilateralmente pelo Estado quanto ao modo de organização e prestação do serviço público, atos condições relacionados à submissão voluntária do particular às regras impostas e, ainda, atos contratuais referentes à existência de um contrato administrativo de licitação que garante o equilíbrio econômico-financeiro entre os interesses em jogo e resguarda os legítimos interesses econômicos do concessionário. 
No mais, a considerar o Princípio da Legalidade como orientador dos atos administrativos praticados pelo poder público nas três esferas de poder, certo é que a entrega de um serviço público em concessão depende da existência prévia de lei que o autorize. E, uma vez sendo promulgada lei autorizadora da outorga do serviço em concessão, segundo determinação constitucional insculpida no artigo 175 da Carta Magna, dever-se-á proceder à licitação, por meio de edital, através do qual eventuais interessados irão se apresentar e, dentre eles, escolhido aquele que oferecer condições mais vantajosas à administração pública (BRASIL, 1988). Ressalte-se, que, embora a Lei $n^{\circ}$ 8987/95 (BRASIL, 1995a) preveja diversas modalidades licitatórias, em se tratando de concessão de serviços públicos, a única admitida é a concorrência, com a ressalva dos casos pontuais em que a legislação previu a possibilidade de leilão, a exemplo da Lei nº 9074/95 (BRASIL, 1995b).

E, sem a pretensão de esgotar o tema, cumpre discorrer quanto às formas de extinção das concessões. Neste particular, prevê a legislação, no artigo 35 da Lei de Concessões (BRASIL, 1995a), o término da concessão pelo advento do termo contratual, a encampação ou resgate (quando o poder público, por critérios de conveniência ou oportunidade, extingue o contrato antes de seu termo final sem que para tanto tenha dado causa o concessionário), a caducidade ou decadência, hipótese em que também há extinção antecipada mas há, neste caso, inadimplência do concessionário e prática de fato caracterizável como grave violação de suas obrigações, rescisão judicial (a pedido do poder concedente ou concessionária quando inadimplente a parte contrária), anulação - situações em que há vício na prática do ato - e falência ou extinção da e empresa concessionária e falecimento ou incapacidade do titular, no caso de empresa individual.

O artigo 195 da Lei $n^{\circ}$ 11.101/05 determina que "a decretação da falência das concessionárias de serviços públicos implica extinção da concessão, na forma da lei”. Referida lei é 8.987/95 a qual, em seu artigo 35, inciso VI, expressamente menciona que a falência é causa de extinção da concessão, situação em que os bens afetados à prestação do serviço público serão revertidos ao poder concedente mediante pagamento de indenização (BRASIL, 1995a, 2005). Não trata a lei, contudo, da hipótese de recuperação judicial, não enquadrando a crise econômica da empresa concessionária de serviço público dentro das situações de decadência ou caducidade, tampouco elencando-a como hipótese autônoma de extinção do contrato de concessão. 
Assim, diante da ausência de vedação legal, tem-se que o pedido e posterior concessão pelo juíza da recuperação judicial à empresa prestadora de serviço público que esteja em crise não pode ensejar, por si só, a extinção da concessão. Ao contrário, permite-se a tais empresas que possam se valer deste procedimento para tentativa de soerguimento de suas atividades e superação da difícil situação em que encontrem.

Neste particular, exceção deve ser feita às concessionárias de energia elétrica por expressa vedação da Lei $n^{\circ}$ 12.767/12 (BRASIL, 2012a), fruto da conversão da medida provisória $n^{\circ}$ 577/2012 (BRASIL, 2012b), a qual preconiza, em seu artigo 18, que ficam vedados os benefícios da recuperação judicial e extrajudicial a tais empresas, enquanto perdurar a concessão.

\section{DA RECUPERAÇÃO JUDICIAL}

\subsection{Conceito e Cabimento}

A respeito da recuperação judicial, dispõe a Lei n ${ }^{\circ}$ 11.101/05 - Lei de Falências e Recuperação Judicial - em seu artigo Art. 47, o seguinte:

\footnotetext{
Art. 47: A recuperação judicial tem por objetivo viabilizar a superação da situação de crise econômico-financeira do devedor, a fim de permitir a manutenção da fonte produtora, do emprego dos trabalhadores e dos interesses dos credores, promovendo, assim, a preservação da empresa, sua função social e o estímulo à atividade econômica (BRASIL, 2005, art. 47).
}

Uma breve leitura do artigo em comento nos evidencia que o fim precípuo da recuperação judicial é o de viabilizar a superação da situação da crise econômico-financeira da empresa, mantendo-a ativa. Daí decorre um dos principais princípios a reger o tema, o da Preservação da Empresa.

Segundo Marcelo Barbosa Sacramone (2018, p. 44), a atividade empresarial deverá ser preservada sempre que possível em razão de sua função social. A empresa gera riqueza econômica, assegura os empregos e a renda e contribui com o crescimento e desenvolvimento social do País, e deverá ser, dessa forma, sempre que possível, preservada.

Assim, desde que atendidos alguns requisitos legais, pode a sociedade empresária requerer a concessão da recuperação judicial e, assim, valer-se de um regime jurídico próprio que lhe conceda benefícios - a exemplo da suspensão das execuções existentes contra si - a fim de se reestruturar, negociar com credores visando a aprovação de um plano para 
pagamento de suas dívidas e, então, reerguer-se, saindo da situação de crise em que se encontrava.

Ademais, quando da análise do pedido de recuperação judicial, a par dos requisitos legais previstos no artigo 51 da Lei $n^{\circ} 11.101 / 05$, a Lei $n^{\circ} 14.112 / 20$ inovou ao acrescentar, no artigo 51-A, a figura da "constatação prévia", instrumento que permite ao juiz, quando entender necessário, nomear perito de sua confiança a fim de atestar as reais condições de funcionamento da empresa e a regularidade da documentação ofertada e, apenas após, decidir quanto ao deferimento do pedido (BRASIL, 2020). O indeferimento da petição inicial, neste momento, apenas é permitido se acaso constatado indícios de uso fraudulento da ação de recuperação judicial.

Neste sentido, o disposto no artigo 51-A da Lei n ${ }^{\circ} 11.101 / 05$ :

Art. 51-A. Após a distribuição do pedido de recuperação judicial, poderá o juiz, quando reputar necessário, nomear profissional de sua confiança, com capacidade técnica e idoneidade, para promover a constatação exclusivamente das reais condições de funcionamento da requerente e da regularidade e da completude da documentação apresentada com a petição inicial.

$\S 1^{\circ}$ A remuneração do profissional de que trata o caput deste artigo deverá ser arbitrada posteriormente à apresentação do laudo e deverá considerar a complexidade do trabalho desenvolvido.

$\S 2^{\circ} \mathrm{O}$ juiz deverá conceder o prazo máximo de 5 (cinco) dias para que o profissional nomeado apresente laudo de constatação das reais condições de funcionamento do devedor e da regularidade documental.

$\S 3^{\circ}$ A constatação prévia será determinada sem que seja ouvida a outra parte e sem apresentação de quesitos por qualquer das partes, com a possibilidade de o juiz determinar a realização da diligência sem a prévia ciência do devedor, quando entender que esta poderá frustrar os seus objetivos.

$\S 4^{\circ} \mathrm{O}$ devedor será intimado do resultado da constatação prévia concomitantemente à sua intimação da decisão que deferir ou indeferir o processamento da recuperação judicial, ou que determinar a emenda da petição inicial, e poderá impugná-la mediante interposição do recurso cabível.

$\S 5^{\circ}$ A constatação prévia consistirá, objetivamente, na verificação das reais condições de funcionamento da empresa e da regularidade documental, vedado o indeferimento do processamento da recuperação judicial baseado na análise de viabilidade econômica do devedor.

$\S 6^{\circ}$ Caso a constatação prévia detecte indícios contundentes de utilização fraudulenta da ação de recuperação judicial, o juiz poderá indeferir a petição inicial, sem prejuízo de oficiar ao Ministério Público para tomada das providências criminais eventualmente cabíveis.

$\S 7^{\circ}$ Caso a constatação prévia demonstre que o principal estabelecimento do devedor não se situa na área de competência do juízo, o juiz deverá determinar a remessa dos autos, com urgência, ao juízo competente (BRASIL, 2005).

Segundo dicção do artigo 48 da Lei $n^{\circ} 11.101 / 05$, poderá requerer a recuperação judicial o devedor que, no momento do pedido, exerça suas atividades há mais de dois anos, 
não seja falido nem tenha obtido concessão de recuperação judicial há menos de cinco anos, bem como cujo administrador ou sócio controlador não tenha sido condenado por crime falimentar.

$\mathrm{O}$ artigo $2^{\mathrm{o}}$ da referida lei, em sentido contrário, exclui da abrangência da recuperação judicial empresa pública e sociedade de economia mista, além de instituição financeira pública ou privada, cooperativa de crédito, consórcio, dentre outras entidades legalmente equiparadas às mencionadas.

Deste modo, possível dizer que não há vedação legal, tanto na Lei de Concessões quanto na Lei de Recuperação de Empresas e Falência, quanto à possibilidade de recuperação judicial de concessionária de serviço público (BRASIL, 1995a, 2005). E tanto é possível que já se valeram da recuperação judicial empresas concessionárias de serviços públicos do ramo de telefonia (Oi), estradas e rodagem (Rodovias do Tietê) e de serviços aeroportuários (Aeroporto Internacional de Viracopos), exemplificativamente.

\subsection{Análise Principiológica e Interpretativa: a recuperação judicial de empresas concessionárias de serviços públicos}

Considerando o escopo do presente trabalho, em que se pretende tecer considerações quanto aos princípios que regem o tema da recuperação judicial de empresas concessionárias de serviços públicos, algumas premissas devem ser traçadas.

A primeira é a de que se deve proceder a uma interpretação de forma sistemática e harmônica de toda a legislação e contratos administrativos que regem as concessões dos serviços públicos prestados pelas empresas em situação de crise, considerando todas essas normas como válidas e eficazes para solução do conflito de interesses posto, e sopesando-se os Princípios da Supremacia do Interesse Público, o Princípio da Continuidade do Serviço Público, da Função Social e da Preservação da Empresa.

A segunda é a de que a função social da empresa, bem como a necessidade de sua preservação, segundo entendo, devem ser ainda mais valoradas quando se está diante de empresa que desempenha a execução, manutenção e ampliação de serviços públicos de extrema relevância.

Para ilustração do tema, transcreve-se trecho da obra do autor Marcelo Barbosa Sacramone (2018): 
Sua preservação é pretendida pela LREF como um modo de se conciliar os diversos interesses afetados com o seu desenvolvimento. Como fonte geradora de bem-estar, a função social da atividade empresarial é justamente se desenvolver e circular riquezas, de modo a permitir a distribuição de dividendos a sócios, mas também de promover a oferta de bens e serviços aos consumidores, aumentar a concorrência entre os agentes econômicos, gerar a oferta de postos de trabalho e o desenvolvimento econômico nacional. A LREF, nesse ponto, rompe com a dinâmica das legislações anteriores para considerar a superação da crise econômico-financeira como um modo de satisfação não apenas de interesses de credores e devedores, o que uma solução simplesmente liquidatória já poderia assegurar. Reconhece-se que a preservação da empresa e sua função social assegura também o atendimento dos interesses de terceiros, dos empregados, dos consumidores e de toda nação (SACRAMONE, 2018, p. 190).

De mais a mais, tem-se que a recuperação judicial não abarca a previsão de paralisação das atividades da empresa, ao contrário, ela busca manter a sociedade em pleno funcionamento mediante a concessão de mecanismos que possibilitem a superação da crise e o exercício de sua atividade em condições econômicas ainda melhores. Em sendo assim, há plena convergência de propósitos entre as finalidades da recuperação judicial e os princípios que norteiam a prestação de serviços públicos pelas empresas concessionárias, aí se inserindo o da continuidade e da eficiência. Busca-se, em última análise, que a recuperação judicial possibilite a melhoria nas condições financeiras das concessionárias de serviço público com a superação da crise e que, deste modo, sejam capazes de continuarem a prestar o serviço público a que se propuseram por meio do contrato de concessão, os quais, como é cediço, devem ser prestados ininterruptamente.

Além do princípio da continuidade, o instituto da recuperação judicial também evidencia a preservação da empresa que, no caso das concessionárias, é mais do que fundamental. E isso porque tais empresas prestam serviço público, que é em sua natureza essencial, de extrema relevância para a coletividade em geral e, por este motivo, devem, no mais das vezes e sempre que possível, serem preservados.

A função social da empresa que é tutelada pela recuperação judicial, do mesmo modo e dentro desta ordem de ideias, também possui intrínseca relação com a prestação do serviço público, já que estes também são regidos pelo princípio da universalidade e, sendo assim, procuram abarcar a totalidade dos indivíduos e evitarem a marginalização social.

De se ressaltar que os princípios ora elencados constituem parâmetros interpretativos ao julgador não apenas quando se está diante das questões afetas às recuperações judiciais de empresas concessionárias de serviço público, mas também, e, principalmente, quando se vê compelido a interpretar as normas dos contratos de concessão, a exemplo daquelas inseridas em favor do poder concedente e que poderiam levar à ruína da concessionária. 
Assim, muito embora seja perfeitamente possível - e até desejável - a existência de cláusulas nos contratos de concessão que protejam o poder concedente, já que é ele o detentor do serviço público e atua, em última análise, em prol dos interesses de toda a sociedade, não podem tais cláusulas, em situações de crise, serem interpretadas de modo simplista.

E isso porque uma interpretação literal de tais cláusulas, que considere tão somente princípios de direito privado, muitas vezes conduzirá à concretização de situações irremediáveis para a concessionária.

Neste particular, e com vistas apenas à ilustração do tema, temos a dicção do artigo 28 da Lei de Concessões, no sentido de que "Nos contratos de financiamento, as concessionárias poderão oferecer em garantia os direitos emergentes da concessão, até o limite que não comprometa a operacionalização e a continuidade da prestação do serviço" (BRASIL, 1995a, art. 28).

A cessão, pela concessionária, em caráter fiduciário, de seus créditos futuros, também é possível segundo dicção do artigo 28-A da mesma lei.

E tal disposição normativa não raras vezes vem repetida no bojo dos contratos de concessão assinados pelo poder concedente e concessionária após o resultado da licitação ou edital, a exemplo do contrato firmado entre AEROPORTOS BRASIL S.A., AEROPORTOS BRASIL - VIRACOPOS S.A. e VIRACOPOS ESTACIONAMENTOS S.A. e o poder concedente, este representado pela AGÊNCIA NACIONAL DE AVIAÇÃO CIVIL. E o que se percebe, comparando-se tanto a Lei de Concessão quanto os contratos de concessão, é que houve por parte do legislador pátrio uma preocupação, ou melhor, uma cautela, em resguardar, nos contratos de financiamento, o oferecimento de garantias por parte da concessionária a limites razoáveis que não comprometam a operacionalização e a continuidade da prestação do serviço.

Tal cautela se justifica, como resta claro, ante a necessidade e imperiosidade do serviço concedido, cuja execução e continuidade está revestida de inegável interesse público.

Em outras palavras, procurou-se tutelar o serviço público concedido frente aos credores com garantia fiduciária, fixando-se como critério um limite que não comprometesse a própria continuação e execução do serviço.

Tal limite, assim, visou salvaguardar a manutenção do serviço ainda nas hipóteses de execução das garantias contratuais prestadas, as quais são, não raras vezes, representadas pela totalidade do fluxo de caixa obtido com a própria prestação do serviço. 
Trata-se, em conclusão, de hipótese legal que prestigia a aplicação dos princípios ora estudados e que deve ser também observada pelo julgador nas situações que lhe forem concretamente submetidas, harmonizando-se, dentro do possível, interesses públicos e privados que levem ao soerguimento da empresa e manutenção na prestação do serviço com competência e eficiência.

\section{CONCLUSÃO}

A prestação de serviços públicos de interesse coletivo e titularizados pelo Estado, conforme dito, pode se dar indiretamente por meio de empresas concessionárias, vencedoras de processo licitatório, através de concessão. Tais empresas, como é cediço, também podem vir a sofrer crises econômico-financeiras no desempenho das atividades que prestam e, assim, estão sujeitas à Lei de Falência e Recuperação Judicial, ressalvadas as exceções já apontadas.

Neste contexto, considerando a relevância do serviço que prestam - já que se trata de serviço público e, portanto, revestidos das características da essencialidade, eficiência e continuidade - tem-se que devem ser interpretadas de forma sistemática e harmônica todas as normas legais que a disciplinam a recuperação judicial das empresas concessionárias.

Assim, os princípios próprios da recuperação judicial, em especial o da Preservação da Empresa, devem ser enaltecidos e efetivamente aplicados quando se tratar de processo judicial que envolva concessionária de serviço público justamente porque, em casos tais, estão presentes a supremacia do interesse público representada pela essencialidade e necessidade da prestação do serviço.

A coexistência de tais princípios também deve ser reconhecida e prestigiada pelo magistrado quando da análise dos contratos de concessão que embasam as relações jurídicas entre poder concedente e concessionária, bem como entre os demais participantes dos contratos de concessão, à exemplo dos financiadores, tudo com vistas a salvaguardar o interesse público que decorre da manutenção em funcionamento de tais concessionárias.

Em resumo, a superação da situação de crise das empresas concessionárias de serviço público é medida desejável e de interesse de toda a coletividade, que deve ser analisada caso a caso sob o prisma dos princípios objeto do estudo.

\section{REFERÊNCIAS}


ALMEIDA, Amador Paes de. Curso de Falência e Recuperação de Empresa. 28. ed. São Paulo: Saraiva, 2017.

BRASIL. Constituição da República Federativa do Brasil de 1988. Brasília, DF:

Presidência da República. Disponível em:

http://www.planalto.gov.br/ccivil_03/constituicao/constituicao.htm. Acesso em: 10 jul. 2021.

BRASIL. Lei $\mathbf{n}^{\circ}$ 11.101 de 2005. Regula a recuperação judicial, a extrajudicial e a falência do empresário e da sociedade empresária. Brasília, DF: Presidência da República. Disponível em: http://www.planalto.gov.br/ccivil_03/_ato2004-2006/2005/lei/111101.htm. Acesso em: 20 jul. 2021.

BRASIL. Lei ${ }^{\circ} \mathbf{1 2 . 7 6 7}$ de 27 de dezembro de 2012. Dispõe sobre a extinção das concessões de serviço público de energia elétrica e a prestação temporária do serviço e sobre a intervenção para adequação do serviço público de energia elétrica, e dá outras providências. Brasília, DF: Presidência da República, 2012a. Disponível em: http://www.planalto.gov.br/ccivil_03/_ato2011-2014/2012/lei/L12767.htm. Acesso em: 27 jul. 2021.

BRASIL. Lei ${ }^{\circ} \mathbf{1 4 . 1 1 2}$ de 24 de dezembro de 2020. Altera as Leis $n^{\circ} 11.101$, de 9 de fevereiro de 2005, 10.522, de 19 de julho de 2002, e 8.929, de 22 de agosto de 1994 e dá outras providências. Brasília, DF: Presidência da República, 2020. Disponível em: http://www.planalto.gov.br/ccivil_03/_ato2019-2022/2020/lei/L14112.htm. Acesso em: 25 jul. 2021.

BRASIL. Lei ${ }^{\circ}$ 4.117 de 27 de agosto de 1962. Institui o Código Brasileiro de Telecomunicações. Brasília, DF: Presidência da República. Disponível em: http://www.planalto.gov.br/ccivil_03/leis/14117compilada.htm. Acesso em: 11 jun. 2021.

BRASIL. Lei $\mathbf{n}^{\circ} \mathbf{5 . 7 8 5}$ de 23 de junho de 1972. Prorroga o prazo das concessões e permissões para a execução dos serviços de radiodifusão sonora que especifica e dá outras providências. Brasília, DF: Presidência da República. Disponível em: http://www.planalto.gov.br/ccivil_03/leis/15785.htm. Acesso em: 10 jun. 2021.

BRASIL. Lei $\mathbf{n}^{\circ} \mathbf{8 . 9 8 7}$ de 13 de fevereiro de 1995. Dispõe sobre o regime de concessão e permissão da prestação de serviços públicos previsto no art. 175 da Constituição Federal, e dá outras providências. Brasília, DF: Presidência da República, 1995a. Disponível em: http://www.planalto.gov.br/ccivil_03/leis/18987compilada.htm. Acesso em: 12 jun. 2021.

BRASIL. Lei ${ }^{\circ}$ 9.074 de 7 de julho de 1995. Estabelece normas para outorga e prorrogações das concessões e permissões de serviços públicos e dá outras providências. Brasília, DF: Presidência da República, 1995b. Disponível em: http://www.planalto.gov.br/ccivil_03/leis/19074cons.htm. Acesso em: 25 jul. 2021.

BRASIL. Medida Provisória $\mathbf{n}^{\circ} 577$ de 29 de agosto de 2012. Dispõe sobre a extinção das concessões de serviço público de energia elétrica e a prestação temporária do serviço, sobre a intervenção para adequação do serviço público de energia elétrica, e dá outras providências. Brasília, DF: Presidência da República, 2012b. Disponível em: http://www.planalto.gov.br/ccivil_03/_ato2011-2014/2012/Mpv/577.htm. Acesso em: 01 ago. 2021. 
CÁRNIO, Daniel; MELO, Alexandre Correa Nasser de. Comentários à Lei de Recuperação de Empresas e Falência. Curitiba: Juruá, 2021.

CHAPUS, René. Droit Administratif General. 6. ed. Paris: Montchrestien, 1992.

COELHO, Fabio Ulhoa. Comentários à Lei de Falência e de Recuperação de Empresas. 14. ed. São Paulo: Rev. Dos Tribunais, 2021.

GASPARINI, Diogenes. Direito Administrativo. 9. ed. São Paulo: Saraiva, 2004.

MARINELA, Fernanda. Direito Administrativo. Volume único. 15. ed. São Paulo: Juspudium, 2021.

MEIRELES, Hely Lopes. Direito Administrativo Brasileiro. 43. ed. São Paulo: Malheiros, 2018.

MELLO, Celso Antonio Bandeira de. Curso de Direito Administrativo. 35. ed. São Paulo: Ed. Juspodium, 2021.

PIETRO, Maria Sylvia Zanella di. Direito Administrativo. 34. ed. São Paulo: Forense, 2021.

SACRAMONE, Marcelo Barbosa. Comentários à lei de recuperação de empresas e falência. São Paulo: Saraiva, 2018.

TOMAZETE: Marlon. Curso de Direito Empresarial. v. 3. Falência e Recuperação de Empresas. São Paulo: Saraiva, 2018.

UZAL, Luiza Seijas. A Recuperação Judicial de Empresas Concessionárias de Serviços Públicos. São Paulo: Insper, 2018. 